\title{
Levantamento florístico e fitossociológico do componente arbóreo de um fragmento de Floresta Estacional Decidual em São Miguel do Oeste, Santa Catarina
}

\author{
Geniane Schneider ${ }^{1 *}$ \\ Fernando Souza Rocha ${ }^{2}$ \\ ${ }^{1}$ Universidade Federal de Santa Catarina, Departamento de Botânica, Laboratória de Anatomia Vegetal - LAVEG. \\ Campus Universitário, Trindade, CEP 88040-900, Florianópolis - SC, Brasil. \\ ${ }^{2}$ Universidade Federal de Santa Catarina, Departamento de Fitotecnia, Laboratório de Ecologia Aplicada - LEAp. \\ Rodovia Admar Gonzaga, 1346, CEP 88034-001, Florianópolis - SC, Brasil \\ * Autor para correspondência \\ geni_tega@yahoo.com.br
}

Submetido em 18/04/2013

Aceito para publicação em 24/03/2014

\section{Resumo}

A cobertura florestal em Santa Catarina encontra-se reduzida e fragmentada e entre as tipologias florestais mais fortemente afetadas está a Floresta Estacional Decidual. Com objetivo de conhecer a composição e estrutura do componente arbóreo de um fragmento de Floresta Estacional foram demarcadas unidades amostrais de 20 x $20 \mathrm{~m}$, totalizando 0,4 ha. As espécies arbóreas com circunferência à altura do peito $(\mathrm{CAP}) \geq 25 \mathrm{~cm}$ foram avaliadas e identificadas. Foram amostrados 205 indivíduos, de 54 espécies, distribuídas em 44 gêneros e 23 famílias. A estimativa da diversidade arbórea pelo índice Shannon-Weaver $\left(H^{\prime}\right)$ resultou em 3,472 (nats) e a equabilidade de Pielou (J') em 0,870. As famílias com maior número de espécies foram Fabaceae, Myrtaceae, Meliaceae, Lauraceae e Sapindaceae e as espécies com as maiores densidades e coberturas foram Nectandra megapotamica (Spreng.) Mez, Sorocea bonplandii (Baill.) W.C. Burger, Lanjouw \& Boer e Ocotea diospyrifolia (Meisn.) Mez. A riqueza e diversidade da amostra situam-se como intermediárias entre aqueles obtidos para fragmentos de Florestas Estacionais Deciduais, nos levantamentos do Inventário Florístico Florestal de Santa Catarina, evidenciando impacto da exploração e fragmentação nesta formação. Apesar do contexto, a área estudada conserva importante parcela das espécies citadas para essa tipologia florestal.

Palavras chave: Diversidade arbórea; Floresta Atlântica; Floresta Estacional; Fragmento florestal; Sul do Brasil

\section{Abstract}

Floristic and phytosociological investigation of trees in a seasonal deciduous forest fragment at São Miguel do Oeste, Santa Catarina. The forests in Santa Catarina have been reduced and fragmented, and seasonal deciduous forests are among the most afflicted. The aim of the investigation was to describe arboreal composition and structure in a seasonal deciduous forest fragment. We established ten sample units of 20x20 $\mathrm{m}$, covering a total area of 0.4 ha. Trees with circumference at breast height $(\mathrm{CBH}) \geq 25 \mathrm{~cm}$ were identified, and species richness and diversity were evaluated. A total of 205 individuals was sampled from 54 species, representing 44 genera and 23 families. Tree diversity was estimated to be 3.472 (nats) using the Shannon-Weiner index $\left(H^{\prime}\right)$, and Pielou's evenness $\left(\mathrm{J}^{\prime}\right)$ was estimated at 0.87 . The families with the largest number of species 
were Fabaceae, Myrtaceae, Meliaceae, Lauraceae and Sapindaceae. The species with the highest importance and coverage values were Nectandra megapotamica (Spreng.) Mez, Sorocea bonplandii (Baill.) W.C. Burger, Lanjouw \& Boer, and Ocotea diospyrifolia (Meisn.) Mez. Species richness and diversity are within the range of values cited for seasonal deciduous forests in the Floristic Forest Inventory of Santa Catarina, which shows the impact of exploration and fragmentation on this habitat. Nevertheless, the studied area has apparently conserved a significant portion of the tree species cited for this forest type.

Key words: Atlantic Forest; Phytosociology; Seasonal Deciduous Forest; Southern Brazil; Tree diversity

\section{Introdução}

O estado de Santa Catarina possuía, até poucas décadas atrás, uma das áreas proporcionalmente mais ricas em florestas no Brasil (MACHADO, 1984). Originariamente, estas florestas cobriam mais de nove milhões de hectares, estendendo-se pela maior parte do território catarinense (FUNDAÇÃO SOS MATA ATLÂNTICA, 2005).

A vegetação encontrada no estado comporta grande quantidade de espécies úteis à indústria madeireira e isso resultou em uma exploração descontrolada, seguida pela expansão da agricultura e pecuária (REITZ et al., 1978), reduzindo as florestas a remanescentes que totalizam atualmente pouco mais de dois milhões de hectares, ou seja, cerca de $23 \%$ da sua área original (FUNDAÇÃO SOS MATA ATLÂNTICA, 1998).

Um dos ecossistemas historicamente mais afetados no estado é a Floresta Estacional Decidual (FED) ou Floresta Estacional do Alto Uruguai (KLEIN 1972; 1978; VELOSO; GÓES-FILHO, 1982). Grande parte das espécies que compõem esta tipologia são características e exclusivas, motivo pelo qual constitui uma formação vegetal muito própria e distinta das demais encontradas no estado (KLEIN, 1978; VELOSO; GÓES-FILHO, 1982).

A FED ocupava uma área considerável, seguindo das margens do rio Uruguai até cerca de $600 \mathrm{~m}$ de altitude ao longo dos vales de seus afluentes. Na altura da foz dos rios Peperi-Guaçu e das Antas, a largura desta formação vegetal em ambos os lados do rio Uruguai era de 30 a 50 km (KLEIN, 1972; SANTA CATARINA, 1991). Atualmente, a área ocupada por esta vegetação encontra-se diminuída, e se estima que este seja um dos ecossistemas mais devastados do Brasil, com o agravante de que no estado de Santa Catarina não existe nenhuma reserva legal desta formação vegetal (RUSCHEL, 2003).
Segundo o Inventário Florístico-Florestal de Santa Catarina, a FED cobre aproximadamente 1.231 $\mathrm{km}^{2}$, equivalente a $16 \%$ de sua área original. É a região fitoecológica mais fragmentada do estado, uma vez que $89 \%$ dos fragmentos têm área de até 50 ha e há poucos fragmentos maiores que 200 ha (VIBRANS et al., 2012b).

O presente estudo foi realizado em um fragmento de FED no oeste de Santa Catarina, com objetivo de caracterizar florística e fitossociologicamente este fragmento.

\section{Material e Métodos}

O estudo foi realizado em um fragmento florestal localizado na linha Dois Irmãos, município de São Miguel do Oeste, Santa Catarina (ca. 26² $45^{\prime} 07,3$ 's; $53^{\circ} 23^{\prime} 53,3^{\prime}$ 'W). Este fragmento possui uma área de aproximadamente 409 ha e pertence ao Exército Brasileiro.

O relevo é caracterizado basicamente pelo Planalto Dissecado pelos Rios Iguaçu/Uruguai, com vales profundos e encostas em patamares. A altitude varia entre 200 e $800 \mathrm{~m}$. Os solos são predominantemente litólicos, com fertilidade natural variável e Terra Bruna Estruturada Húmica, Terra Bruna Estruturada, Terra Bruna Intermediária para Terra Roxa Estruturada e Terra Roxa Estruturada, que consistem em solos profundos e bem drenados, com baixa fertilidade (SANTA CATARINA, 1991). De acordo com o sistema de Köppen o clima se enquadra no grupo Cfa Mesotérmico, uma vez que as temperaturas médias do mês mais frio estão abaixo de $18^{\circ} \mathrm{C}$ e são superiores a $3^{\circ} \mathrm{C}$ (SANTA CATARINA, 1991).

A vegetação é composta pela FED, marcada pela perda de grande parte das folhas durante o inverno. Klein $(1972 ; 1978)$ destacou a homogeneidade da FED, 
sendo caracterizada por três estratos: superior (dossel), formado principalmente por espécies perenifólias; emergente, composto principalmente por espécies decíduas e inferior, constituído de arvoretas.

Para o estudo da comunidade arbórea foi delimitada uma área de 4,2 ha de FED, dividida em 105 parcelas quadradas de $20 \times 20 \mathrm{~m}$, das quais sortearam-se dez, totalizando 0,4 ha de área amostral. Todos os indivíduos arbóreos vivos com circunferência à altura do peito (CAP) $\geq 25 \mathrm{~cm}$ foram amostrados e coletados em fase reprodutiva, se possível, e/ou vegetativa. Os indivíduos ramificados que possuíam pelo menos uma das ramificações com $\mathrm{CAP} \geq 25 \mathrm{~cm}$ também foram amostrados, sendo anotado o diâmetro de todos os fustes. Os exemplares localizados sobre as bordas das unidades amostrais foram considerados, desde que mais da metade de sua área basal estivesse dentro da parcela.

Cada indivíduo amostrado foi marcado com uma etiqueta numerada, identificado no campo ou posteriormente no laboratório. Cada indivíduo teve sua altura total estimada (com arredondamento a cada 0,5 $\mathrm{m})$, por meio de comparação com uma vara de coleta com altura conhecida, e seu valor de CAP registrado. A coleta e a herborização do material testemunho seguiram as recomendações de Fidalgo e Bononi (1984). Exsicatas do material botânico fértil coletado na área foram depositadas no acervo do Herbário Flor da UFSC - Universidade Federal de Santa Catarina.

A identificação do material botânico realizou-se por meio de consultas à literatura especializada, comparação com material de herbário e, quando necessário, envio a especialistas. As famílias de angiospermas seguiram o APG III (2009).

A análise dos dados para a determinação da estrutura da vegetação foi realizada através dos seguintes parâmetros fitossociológicos (MARTINS, 1991): densidade absoluta (DA), densidade relativa (DR), frequência absoluta (FA), frequência relativa (FR), dominância absoluta e relativa, a partir das medidas da área basal (AB), índice de valor de importância (IVI) e índice de valor de cobertura (IVC). Também foram estimados os parâmetros de diversidade através dos índices de Shannon e Weaver (1949) e de equabilidade de Pielou (1969).
Para auxiliar na determinação do estádio sucessional do fragmento estudado foi utilizado um cálculo proposto por Sevegnani et al. (2012):

$$
\begin{gathered}
\mathrm{Y}=\left(0,0287462 \cdot \mathrm{N}_{\text {sp.arb }}\right)+(-0,000946 \cdot \mathrm{DA})+ \\
(0,1450475 \cdot \mathrm{AB})
\end{gathered}
$$

Onde, $\left(\mathrm{N}_{\text {sp.arb }}\right)$ refere-se número de espécies. Segundo Sevegnani et al. (2012) se $Y<3,86$, o remanescente pode ser classificado como estádio sucessional médio e se Y > 3,86, o estádio é avançado.

\section{Resultados}

Foram amostrados 205 indivíduos, distribuídos em 54 espécies, 44 gêneros e 23 famílias (Tabela 1). As famílias com maior número de espécies foram Fabaceae (nove), seguida de Meliaceae e Myrtaceae (cinco), Lauraceae e Sapindaceae (quatro), Euphorbiaceae e Solanaceae (três). As famílias com maior número de indivíduos também foram Fabaceae (38), seguida por Lauraceae (30) e Meliaceae (24). Doze famílias foram representadas por apenas uma espécie cada, correspondendo a $52,17 \%$ do total de espécies.

Foram amostrados 205 indivíduos, valor que corresponde a, aproximadamente, 512 indivíduos/ ha. As espécies com maior densidade absoluta foram Sorocea bonplandii, Nectandra megapotamica, Syagrus romanzoffiana e Trichilia claussenii. Vinte e quatro espécies $(45,28 \%)$ foram representadas por apenas um indivíduo (Tabela 1).

A área basal total foi de $29,5 \mathrm{~m}^{2} / \mathrm{ha}$, considerando todos os indivíduos da amostragem (Tabela 2). As espécies com maiores índices de dominância por área basal foram Nectandra megapotamica $(14,88 \%)$ e Ocotea diospyrifolia $(8,97 \%)$. Outras três espécies de destaque foram Diatenopteryx sorbifolia (6,11\%), Parapiptadenia rigida $(5,08 \%)$ e Holocalyx balansae $(4,99 \%)$, pois apesar dos poucos indivíduos, apresentaram área basal maior que as demais. Chrysophyllum marginatum (4,35\%) e Lonchocarpus muehlbergianus (4,62\%) também apresentaram área basal expressiva. As demais 47 espécies amostradas apresentaram valores individuais menores que $0,50 \mathrm{~m}^{2} /$ ha, totalizando $51,06 \%$ da área basal total. 
TABELA 1: Famílias e espécies amostradas no levantamento fitossociológico do componente arbóreo em Floresta Estacional Decidual em São Miguel do Oeste (SC), com respectivos nomes populares, número de indivíduos amostrados e grupo ecológico, conforme Schorn et al. (2012a; 2012b) e Meyer et al. (2012). P = pioneira, SE = secundária e C = climácica.

\begin{tabular}{|c|c|c|c|c|}
\hline Família & Nome científico & Nome Popular & $\mathrm{n}^{0}$ ind. & $\begin{array}{c}\text { Grupo } \\
\text { ecológico }\end{array}$ \\
\hline Annonaceae & Annona sp. 1 & araticum & 2 & - \\
\hline Apocynaceae & Rauvolfia sellowii Müll. Arg. & - & 1 & SE \\
\hline Araliaceae & $\begin{array}{l}\text { Schefflera morototoni (Aubl.) Maguire, Steyerm., \& } \\
\text { Frodin }\end{array}$ & caixeta & 1 & SE \\
\hline Arecaceae & Syagrus romanzoffiana (Cham.) Glassman & jerivá & 11 & $\mathrm{P}$ \\
\hline Boraginaceae & Cordia ecalyculata Vell. & louro-mole & 2 & SE \\
\hline Cannabaceae & Trema micrantha (L.) Blume & grandiúva & 1 & $\mathrm{P}$ \\
\hline \multirow[t]{3}{*}{ Euphorbiaceae } & Gymnanthes concolor (Spreng). Müll. Arg. & laranjeira-do-mato & 6 & $\mathrm{C}$ \\
\hline & Sapium glandulosum (L.) Morong & pau-de-leite & 1 & $\mathrm{P}$ \\
\hline & Sebastiania brasiliensis Spreng. & leiteiro & 7 & $\mathrm{P}$ \\
\hline \multirow[t]{9}{*}{ Fabaceae } & Albizia edwallii (Hoehne) Barneby \& J. W. Grimes & angico-branco & 4 & SE \\
\hline & Apuleia leiocarpa (Vogel) J. F. Macbr & grápia & 7 & $\mathrm{P}$ \\
\hline & Holocalyx balansae Micheli & alecrim & 2 & $\mathrm{P}$ \\
\hline & Inga marginata Willd. & ingá-feijão & 2 & $\mathrm{P}$ \\
\hline & Lonchocarpus campestris Mart. ex Benth & rabo-de-bugio & 8 & SE \\
\hline & Lonchocarpus muehlbergianus Hassl. & rabo-de-macaco & 10 & SE \\
\hline & Machaerium stipitatum (DC.) Vogel & farinha-seca & 1 & SE \\
\hline & Myrocarpus frondosus Allemão & cabreúva & 1 & SE \\
\hline & Parapiptadenia rigida (Benth.) Brenan & angico-vermelho & 3 & SE \\
\hline \multirow[t]{4}{*}{ Lauraceae } & Nectandra lanceolata Nees \& Mart. & canela-amarela & 1 & SE \\
\hline & Nectandra megapotamica (Spreng.) Mez & canela-merda & 20 & $\mathrm{P}$ \\
\hline & Ocotea diospyrifolia (Meisn.) Mez & canela-amarela & 8 & $\mathrm{C}$ \\
\hline & Ocotea sp. 1 & canela & 1 & - \\
\hline Loganiaceae & Strychnos brasiliensis (Spreng.) Mart & anzol-de-lontra & 6 & SE \\
\hline \multirow[t]{5}{*}{ Meliaceae } & Cabralea canjerana (Vell.) Mart. & canjerana & 6 & $\mathrm{SE}$ \\
\hline & Cedrela fissilis Vell. & cedro & 5 & SE \\
\hline & Guarea macrophylla Vahl & catiguá morcego & 1 & SE \\
\hline & Trichilia catigua A. Juss & catiguá-vermelho & 1 & $\mathrm{C}$ \\
\hline & Trichilia claussenii C. DC. & catiguá & 11 & SE \\
\hline \multirow[t]{3}{*}{ Moraceae } & Ficus luschnathiana (Miq.) Miq. & figueira & 1 & SE \\
\hline & Maclura tinctoria (L.) D. Don ex Steud. & & 1 & - \\
\hline & $\begin{array}{l}\text { Sorocea bonplandii (Baill.) W.C. Burger, Lanjouw \& } \\
\text { Boer }\end{array}$ & cincho & 21 & SE \\
\hline Primulaceae & Myrsine guianensis (Aubl.) Kuntze & capororoca & 4 & $\mathrm{P}$ \\
\hline \multirow[t]{4}{*}{ Myrtaceae } & Campomanesia xanthocarpa Mart. ex O. Berg & guabiroba & 1 & SE \\
\hline & Eugenia burkartiana (D. Legrand) D. Legrand & - & 1 & $\mathrm{C}$ \\
\hline & Eugenia involucrata DC. & cerejeira & 1 & SE \\
\hline & Eugenia ramboi D. Legrand & batinga & 2 & $\mathrm{P}$ \\
\hline Phytolaccaceae & Seguieria aculeata Jacq. & cipó-umbu & 1 & SE \\
\hline Rubiaceae & Rubiaceae sp. 1 & - & 1 & - \\
\hline
\end{tabular}




\begin{tabular}{|c|c|c|c|c|}
\hline \multirow[t]{2}{*}{ Rutaceae } & Balfourodendron riedelianum (Engl.) Engl. & pau-marfim & 2 & SE \\
\hline & Pilocarpus pennatifolius Lem. & jaborandi & 1 & $\mathrm{C}$ \\
\hline \multirow[t]{2}{*}{ Salicaceae } & Casearia decandra Jacq. & guaçatunga & 3 & SE \\
\hline & Casearia sylvestris Sw. & chá-de-bugre & 4 & SE \\
\hline \multirow[t]{4}{*}{ Sapindaceae } & $\begin{array}{l}\text { Allophylus edulis (A. St.-Hil., A. Juss. \& Cambess.) } \\
\text { Hieron. ex Niederl. }\end{array}$ & chal-chal & 2 & SE \\
\hline & Diatenopteryx sorbifolia Radlk. & maria-preta & 2 & $\mathrm{P}$ \\
\hline & Matayba elaeagnoides Radlk. & camboatá-branco & 1 & SE \\
\hline & Matayba sp. 1 & camboatá & 1 & - \\
\hline \multirow[t]{2}{*}{ Sapotaceae } & $\begin{array}{l}\text { Chrysophyllum gonocarpum (Mart. \& Eichler ex Miq.) } \\
\text { Engl. }\end{array}$ & aguaí & 10 & $\mathrm{P}$ \\
\hline & Chrysophyllum marginatum (Hook. \& Arn.) Radlk. & aguaí-vermelho & 7 & $\mathrm{P}$ \\
\hline Simaroubaceae & Picrasma crenata (Vell.) Engl. & pau-amargo & 1 & SE \\
\hline \multirow[t]{3}{*}{ Solanaceae } & Cestrum intermedium Sendtn. & coerana & 1 & SE \\
\hline & Solanum mauritianum Scop. & fumeiro-brabo & 2 & SE \\
\hline & Lycianthes rantonnei (Carrière) Bitter & - & 2 & - \\
\hline Styracaceae & Styrax leprosus Hook. \& Arn. & carne-de-vaca & 1 & SE \\
\hline
\end{tabular}

TABELA 2: Parâmetros fitossociológicos calculados para o componente arbóreo amostrado na Floresta Estacional Decidual em São Miguel do Oeste (SC) (DA = densidade absoluta, $\mathrm{DR}=$ densidade relativa, $\mathrm{FA}=$ frequência absoluta, $\mathrm{FR}=$ frequência relativa, $\mathrm{Abi}$ = área basal da espécie $\mathrm{i}, \mathrm{DoR}=$ dominância relativa, $\mathrm{IVI}=$ índice de valor de importância e IVC = índice de valor de cobertura).

\begin{tabular}{llcccccccc}
\hline & \multicolumn{1}{c}{ Espécie } & $\begin{array}{c}\text { DA (ind. } \\
\text { ha) }\end{array}$ & $\begin{array}{c}\text { DR } \\
(\mathbf{\%})\end{array}$ & $\begin{array}{c}\text { FA } \\
\mathbf{( \% )}\end{array}$ & $\begin{array}{c}\text { FR } \\
\mathbf{( \% )}\end{array}$ & $\begin{array}{c}\text { Abi } \\
(\mathbf{m} \text { /ha) }\end{array}$ & $\begin{array}{c}\text { DoR } \\
(\mathbf{\%})\end{array}$ & $\begin{array}{c}\text { IVI } \\
(\mathbf{\%})\end{array}$ & IVC \\
\hline 1 & Nectandra megapotamica & 50,00 & 9,76 & 100 & 6,67 & 4,35 & 14,88 & 10,43 & 24,63 \\
2 & Sorocea bonplandii & 52,50 & 10,24 & 80 & 5,33 & 0,58 & 1,97 & 5,85 & 12,22 \\
3 & Ocotea diospyrifolia & 20,00 & 3,90 & 60 & 4,00 & 2,63 & 8,97 & 5,63 & 12,88 \\
4 & Lonchocarpus muehlbergianus & 25,00 & 4,88 & 60 & 4,00 & 1,35 & 4,62 & 4,50 & 9,49 \\
5 & Chrysophyllum gonocarpum & 25,00 & 4,88 & 60 & 4,00 & 1,08 & 3,69 & 4,19 & 8,57 \\
6 & Lonchocarpus campestris & 20,00 & 3,90 & 70 & 4,67 & 1,18 & 3,98 & 4,18 & 7,89 \\
7 & Chrysophyllum marginatum & 17,50 & 3,41 & 70 & 4,67 & 1,28 & 4,35 & 4,14 & 7,76 \\
8 & Trichilia claussenii & 27,50 & 5,37 & 80 & 5,33 & 0,40 & 1,38 & 4,03 & 6,74 \\
9 & Syagrus romanzoffiana & 27,50 & 5,37 & 60 & 4,00 & 0,73 & 2,51 & 3,96 & 7,87 \\
10 & Apuleia leiocarpa & 17,50 & 3,41 & 60 & 4,00 & 1,13 & 3,89 & 3,77 & 7,30 \\
11 & Cabralea canjerana & 15,00 & 2,93 & 60 & 4,00 & 1,05 & 3,62 & 3,52 & 6,55 \\
12 & Parapiptadenia rigida & 7,50 & 1,46 & 30 & 2,00 & 1,48 & 5,08 & 2,85 & 6,54 \\
13 & Diatenopteryx sorbifolia & 5,00 & 0,98 & 20 & 1,33 & 1,78 & 6,11 & 2,80 & 7,08 \\
14 & Albizia edwallii & 10,00 & 1,95 & 40 & 2,67 & 1,08 & 3,70 & 2,77 & 5,65 \\
15 & Sebastiana brasiliensis & 17,50 & 3,41 & 50 & 3,33 & 0,30 & 0,99 & 2,58 & 4,41 \\
16 & Holocalyx balansae & 5,00 & 0,98 & 20 & 1,33 & 1,45 & 4,99 & 2,43 & 5,96 \\
17 & Strychnos brasiliensis & 15,00 & 2,93 & 40 & 2,67 & 0,35 & 1,17 & 2,25 & 4,09 \\
18 & Cedrela fissilis & 12,50 & 2,44 & 40 & 2,67 & 0,45 & 1,58 & 2,23 & 4,02 \\
19 & Gymnanthes concolor & 15,00 & 2,93 & 40 & 2,67 & 0,10 & 0,30 & 1,97 & 3,23 \\
20 & Casearia sylvestris & 10,00 & 1,95 & 20 & 1,33 & 0,55 & 1,92 & 1,73 & 3,87 \\
21 & Nectandra lanceolata & 2,50 & 0,49 & 10 & 0,67 & 1,10 & 3,77 & 1,64 & 4,25 \\
22 & Rauvolfia sellowii & 2,50 & 0,49 & 10 & 0,67 & 1,05 & 3,61 & 1,59 & 4,09 \\
23 & Myrsine guianensis & 10,00 & 1,95 & 30 & 2,00 & 0,23 & 0,80 & 1,58 & 2,75 \\
24 & Casearia decandra & 7,50 & 1,46 & 30 & 2,00 & 0,10 & 0,30 & 1,26 & 1,77 \\
25 & Balfourodendron riedelianum & 5,00 & 0,98 & 20 & 1,33 & 0,33 & 1,15 & 1,15 & 2,12
\end{tabular}




\begin{tabular}{|c|c|c|c|c|c|c|c|c|c|}
\hline 26 & Styrax leprosus & 2,50 & 0,49 & 10 & 0,67 & 0,68 & 2,28 & 1,15 & 2,77 \\
\hline 27 & Allophylus edulis & 5,00 & 0,98 & 20 & 1,33 & 0,23 & 0,81 & 1,04 & 1,78 \\
\hline 28 & Cordia ecalyculata & 5,00 & 0,98 & 20 & 1,33 & 0,10 & 0,33 & 0,88 & 1,31 \\
\hline 29 & Annona sp. 1 & 5,00 & 0,98 & 20 & 1,33 & 0,08 & 0,29 & 0,87 & 1,26 \\
\hline 30 & Eugenia ramboi & 5,00 & 0,98 & 20 & 1,33 & 0,08 & 0,22 & 0,84 & 1,20 \\
\hline 31 & Inga marginata & 5,00 & 0,98 & 20 & 1,33 & 0,05 & 0,18 & 0,83 & 1,16 \\
\hline 32 & Schefflera morototoni & 2,50 & 0,49 & 10 & 0,67 & 0,35 & 1,19 & 0,78 & 1,68 \\
\hline 33 & Lycianthes rantonnei & 5,00 & 0,98 & 10 & 0,67 & 0,18 & 0,59 & 0,75 & 1,57 \\
\hline 34 & Ocotea $\mathrm{sp} .1$ & 2,50 & 0,49 & 10 & 0,67 & 0,30 & 1,07 & 0,74 & 1,55 \\
\hline 35 & Solanum mauritianum & 5,00 & 0,98 & 10 & 0,67 & 0,08 & 0,22 & 0,62 & 1,19 \\
\hline 36 & Cestrum intermedium & 2,50 & 0,49 & 10 & 0,67 & 0,18 & 0,57 & 0,57 & 1,05 \\
\hline 37 & Maclura tinctoria & 2,50 & 0,50 & 10 & 0,67 & 0,13 & 0,40 & 0,52 & 0,90 \\
\hline 38 & Rubiaceae sp. 1 & 2,50 & 0,49 & 10 & 0,67 & 0,10 & 0,36 & 0,51 & 0,85 \\
\hline 39 & Matayba elaeagnoides & 2,50 & 0,49 & 10 & 0,67 & 0,08 & 0,29 & 0,48 & 0,78 \\
\hline 40 & Ficus luschnathiana & 2,50 & 0,49 & 10 & 0,67 & 0,08 & 0,25 & 0,47 & 0,73 \\
\hline 41 & Pilocarpus pennatifolius & 2,50 & 0,49 & 10 & 0,67 & 0,08 & 0,24 & 0,46 & 0,73 \\
\hline 42 & Sapium glandulosum & 2,50 & 0,49 & 10 & 0,67 & 0,08 & 0,24 & 0,46 & 0,73 \\
\hline 43 & Picrasma crenata & 2,50 & 0,49 & 10 & 0,67 & 0,05 & 0,18 & 0,44 & 0,67 \\
\hline 44 & Guarea macrophylla & 2,50 & 0,49 & 10 & 0,67 & 0,05 & 0,16 & 0,44 & 0,64 \\
\hline 45 & Trichilia catigua & 2,50 & 0,49 & 10 & 0,67 & 0,05 & 0,14 & 0,43 & 0,63 \\
\hline 46 & Seguieria aculeata & 2,50 & 0,49 & 10 & 0,67 & 0,05 & 0,13 & 0,43 & 0,62 \\
\hline 47 & Eugenia sp. 1 & 2,50 & 0,49 & 10 & 0,67 & 0,03 & 0,09 & 0,41 & 0,58 \\
\hline 48 & Myrocarpus frondosus & 2,50 & 0,49 & 10 & 0,67 & 0,03 & 0,08 & 0,41 & 0,57 \\
\hline 49 & Trema micrantha & 2,50 & 0,49 & 10 & 0,67 & 0,03 & 0,07 & 0,41 & 0,56 \\
\hline 50 & Machaerium stipitatum & 2,50 & 0,49 & 10 & 0,67 & 0,03 & 0,07 & 0,41 & 0,56 \\
\hline 51 & Campomanesia xanthocarpa & 2,50 & 0,49 & 10 & 0,67 & 0,03 & 0,07 & 0,41 & 0,56 \\
\hline 52 & Matayba sp. 1 & 2,50 & 0,49 & 10 & 0,67 & 0,03 & 0,07 & 0,41 & 0,56 \\
\hline 53 & Eugenia burkartiana & 2,50 & 0,49 & 10 & 0,67 & 0,03 & 0,06 & 0,41 & 0,55 \\
\hline \multirow[t]{2}{*}{54} & Eugenia involucrata & 2,50 & 0,49 & 10 & 0,67 & 0,03 & 0,05 & 0,40 & 0,54 \\
\hline & & 512,5 & 100 & 1500 & 100 & 29,25 & 100 & 100 & 200 \\
\hline
\end{tabular}

As espécies com maior frequência relativa foram Nectandra megapotamica (6,67\%), Sorocea bonplandii (5,33\%) e Trichilia claussenii (5,33\%). Deve-se destacar a frequência desta última, visto que é representada por um número relativamente pequeno de indivíduos na área amostrada. Outras espécies frequentes foram Chrysophyllum marginatum (4,67\%), Lonchocarpus campestris (4,67\%), Chrysophyllum gonocarpum (4\%), Lonchocarpus muehlbergianus (4\%) e Ocotea diospyrifolia (4\%) (Tabela 2).

Os maiores valores de importância e cobertura foram apresentados por Nectandra megapotamica, Ocotea diospyrifolia e Sorocea bonplandii. Ocotea diospyrifolia, apesar de apresentar um menor número de indivíduos em comparação com $N$. megapotamica e $S$. bonplandii, possui indivíduos de grande porte.
Outras espécies importantes foram Lonchocarpus muehlbergianus e Chrysophyllum gonocarpum.

A estimativa da diversidade arbórea pelo índice $(H$ ') Shannon-Weaver resultou em 3,472 (nats) e a equabilidade J' de Pielou em 0,870 . Se o critério mínimo de inclusão for alterado de $25 \mathrm{~cm}$ para $30 \mathrm{~cm}$ de CAP ocorre uma pequena redução no número de espécies (uma espécie) e um aumento nos índices de diversidade: $\mathrm{H}^{\prime}=3,50$ (nats) e $\mathrm{J}^{\prime}=0,880$ (Tabela 3 ).

Através da distribuição dos indivíduos amostrados em classes de diâmetro foi possível observar uma predominância na primeira, segunda e terceira classes, correspondendo a 76,77\% da amostra total, com diâmetros à altura do peito entre 7 e $28 \mathrm{~cm}$ (Figura 1). O maior diâmetro encontrado foi de 85,99 cm (Diatenopteryx sorbifolia). 
TABELA 3: Dados de alguns levantamentos florísticos e fitossociológicos realizados em florestas estacionais em alguns estados do Brasil (DAP= diâmetro à altura do peito mínimo para a inclusão, $H^{\prime}=$ índice de diversidade de Shannon-Weaver, J'= equabilidade de Pielou).

\begin{tabular}{|c|c|c|c|c|c|c|c|c|c|}
\hline Cidade (Estado) & $\begin{array}{l}\text { Método amostral } \\
\text { (Área em ha) }\end{array}$ & $\begin{array}{c}\text { Tipo de formação } \\
\text { florestal }\end{array}$ & $\begin{array}{l}\text { DAP } \\
(\mathrm{cm}) \\
\end{array}$ & $\begin{array}{c}N^{0} \\
\text { famílias }\end{array}$ & $\begin{array}{c}\mathrm{N}^{0} \\
\text { gêneros }\end{array}$ & $\begin{array}{c}\mathbf{N}^{0} \\
\text { espécies }\end{array}$ & $\boldsymbol{H}^{\prime}$ & $\mathbf{J}^{\prime}$ & Referência \\
\hline $\begin{array}{l}\text { São Domingos (GO) } \\
13^{\circ} 49^{\prime} 34^{\prime \prime} \text { e } 46^{\circ} 41^{\prime} 55^{\prime \prime} \mathrm{W}\end{array}$ & $\begin{array}{l}\text { Parcelas } \\
\text { (1) }\end{array}$ & $\begin{array}{l}\text { Floresta Estacional } \\
\text { Decidual }\end{array}$ & $\leq 5$ & 21 & 31 & 36 & 2,99 & 0,83 & $\begin{array}{l}\text { Silva e Scariot } \\
\text { (2003) }\end{array}$ \\
\hline Derrubadas (RS) & Quadrantes & & $\leq 10$ & 12 & - & 60 & 3,52 & - & \\
\hline $27^{\circ} 20^{\prime} \mathrm{S}$ e $53^{\circ} 40^{\prime} \mathrm{W}$ & 107 (pontos) & $\begin{array}{c}\text { Floresta Estacional } \\
\text { Decidual }\end{array}$ & & & & & & & $\begin{array}{l}\text { Vasconcellos } \\
\text { et al. (1992) }\end{array}$ \\
\hline $\begin{array}{l}\text { Vale do Sol (RS) } \\
29^{\circ} 34^{\prime} \text { S e } 52^{\circ} 40^{\prime} \mathrm{W}\end{array}$ & $\begin{array}{l}\text { Parcelas } \\
\text { (1) }\end{array}$ & Floresta Estacional & $\leq 5$ & 23 & 46 & 55 & 2,24 & 0,56 & $\begin{array}{l}\text { Jarenkow } \\
\text { e Waechter } \\
(2001)\end{array}$ \\
\hline Santa Tereza (RS) & Parcela & Floresta Fstacional & $\leq 3,2$ & 21 & 37 & 42 & & & $\begin{array}{l}\text { Vaccaro et al. } \\
\text { (1999) }\end{array}$ \\
\hline $29^{\circ} 09^{\prime} 28^{\prime \prime}$ S e $51^{\circ} 42^{\prime} 05^{\prime \prime} \mathrm{W}$ & $(0,6)$ & Decidual & & & & & 2,91 & - & \\
\hline $29^{\circ} 09^{\prime} 29^{\prime \prime S}$ e $51^{\circ} 41^{\prime} 49^{\prime \prime} \mathrm{W}$ & & & & & & & 2,75 & - & \\
\hline $29^{\circ} 11^{\prime} 00^{\prime \prime}$ S e $51^{\circ} 43^{\prime} 40^{\prime \prime} \mathrm{W}$ & & & & & & & 2,72 & - & \\
\hline $\begin{array}{l}\text { Camaquã (RS) } \\
30^{\circ} 41^{\prime} \text { S e } 51^{\circ} 53^{\prime} \mathrm{W}\end{array}$ & $\begin{array}{l}\text { Parcelas } \\
\text { (1) }\end{array}$ & $\begin{array}{l}\text { Floresta Estacional } \\
\text { Semidecidual } \\
\text { Submontana }\end{array}$ & $\leq 5$ & 34 & 55 & 69 & 3,20 & 0,75 & $\begin{array}{l}\text { Jurinitz e } \\
\text { Jarenkow } \\
(2003)\end{array}$ \\
\hline Jaguari (RS) & $\begin{array}{l}\text { Parcelas } \\
\qquad(1,4)\end{array}$ & $\begin{array}{l}\text { Floresta Estacional } \\
\text { Decidual }\end{array}$ & $\leq 9,5$ & 28 & 45 & 54 & 3,63 & - & $\begin{array}{l}\text { Hack et al. } \\
(2005)\end{array}$ \\
\hline $\begin{array}{l}\text { Santa Maria (RS) } \\
29^{\circ} 43^{\prime} 44^{\prime \prime} \text { S e } \\
53^{\circ} 42^{\prime} 44^{\prime \prime} \mathrm{W}\end{array}$ & $\begin{array}{l}\text { Parcelas } \\
\text { (1) }\end{array}$ & $\begin{array}{l}\text { Floresta Estacional } \\
\text { Decidual }\end{array}$ & $\leq 9,55$ & 26 & 45 & 51 & - & - & $\begin{array}{l}\text { Farias et al. } \\
\text { (1994) }\end{array}$ \\
\hline $\begin{array}{l}\text { Derrubadas (RS) } \\
27^{\circ} 11^{\prime} 24^{\prime \prime} \mathrm{S} \mathrm{e} \\
53^{\circ} 51^{\prime} 03^{\prime \prime} \mathrm{W}\end{array}$ & $\begin{array}{l}\text { Quadrantes } \\
141 \text { (pontos) }\end{array}$ & $\begin{array}{l}\text { Floresta Estacional } \\
\text { Decidual }\end{array}$ & $\leq 5$ & 37 & - & 78 & 3,73 & 0,86 & $\begin{array}{l}\text { Ruschel et al. } \\
\text { (2006) }\end{array}$ \\
\hline
\end{tabular}


FIGURA 1: Proporção de indivíduos arbóreos amostrados na Floresta Estacional Decidual em São Miguel do Oeste (SC), por classes de diâmetro de $7 \mathrm{~cm}$.

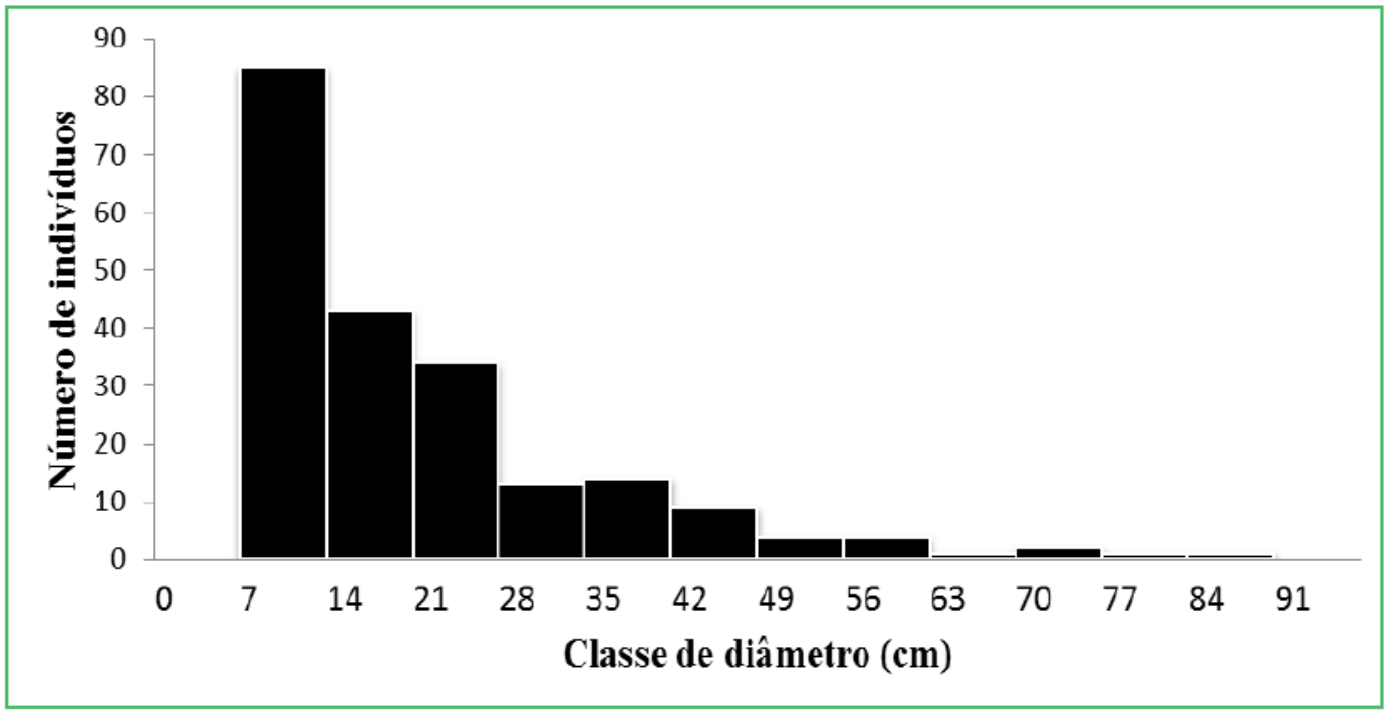

Com relação à estrutura vertical da floresta, os indivíduos amostrados foram agrupados segundo suas alturas estimadas (Figura 2). Foram observados picos nítidos de indivíduos entre 5 e $12 \mathrm{~m}$, incluindo $68,5 \%$ dos indivíduos amostrados. Esses picos são seguidos por outros que se encontram entre 17 e $20 \mathrm{~m}(13,2 \%)$, em $25 \mathrm{~m}(1,5 \%)$ e em $30 \mathrm{~m}(1,5 \%)$ de altura. A maior altura estimada foi de $30 \mathrm{~m}$ para Apuleia leiocarpa, Chrysophyllum marginatum e Parapiptadenia rigida.

\section{Discussão}

A riqueza encontrada neste trabalho foi semelhante àquela verificada nos trabalhos de Farias et al. (1994), Jarenkow e Waechter (2001) e Hack et al. (2005), apesar da área amostral do presente estudo ter sido menos extensa. Já os levantamentos realizados por Jurinitz e Jarenkow (2003) e Ruschel et al. (2006) apresentaram uma maior riqueza de espécies, enquanto

FIGURA 2: Distribuição vertical do componente arbóreo da Floresta Estacional Decidual em São Miguel do Oeste (SC), considerando-se o número de indivíduos total para cada altura estimada.

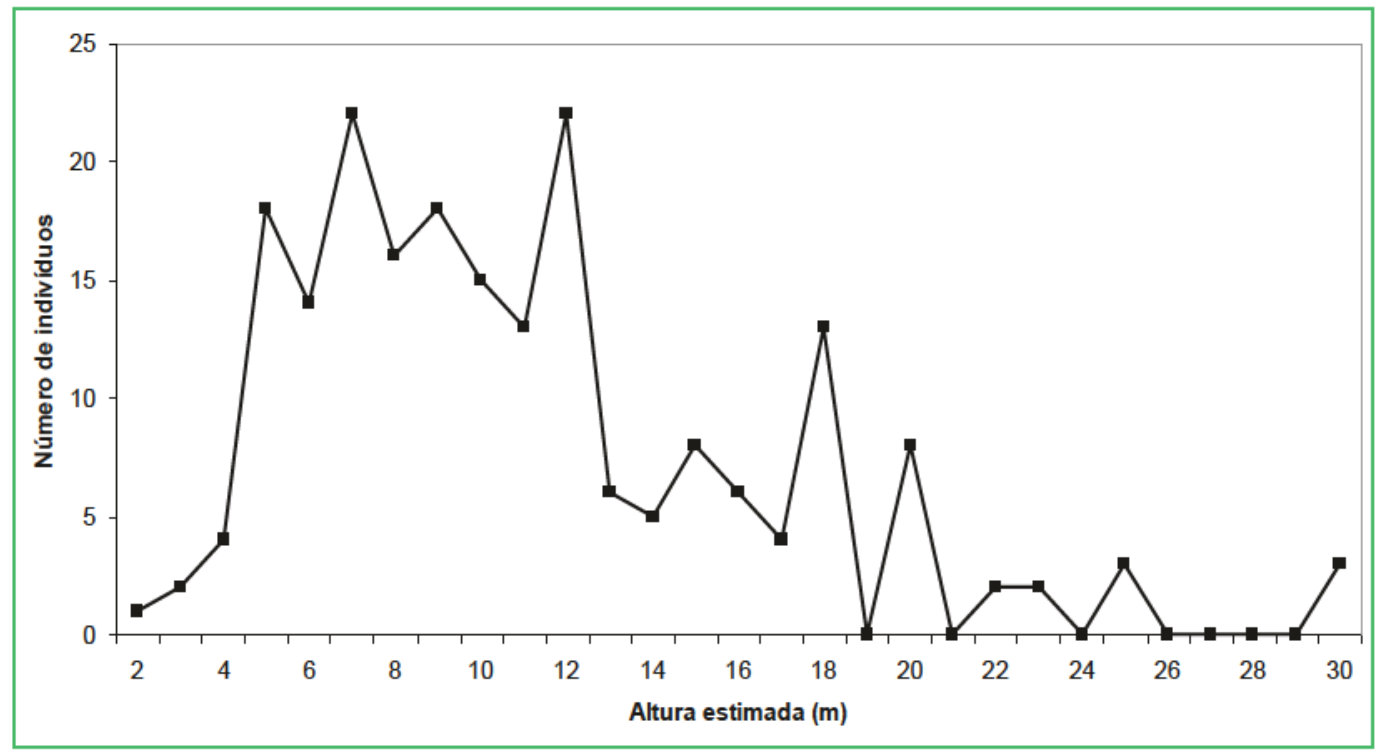


os resultados de Belotti et al. (2002) indicaram menor riqueza (Tabela 3). É importante destacar que nesses trabalhos foram empregados diferentes esforços amostrais e metodologias. Além disso, o trabalho de Belotti et al. (2002) foi realizado em uma floresta ciliar que apresenta diferenças em sua estrutura e florística, dificultando a comparação com outras áreas (RODRIGUES; SHEPHERD, 2001; JURINITZ; JARENKOW, 2003).

No Inventário Florestal de Santa Catarina, a riqueza variou de 14 a 60 espécies nos 78 fragmentos de FED amostrados, com média de 38 espécies para o componente arbustivo/arbóreo. Segundo Vibrans et al. (2012c), a riqueza geral registrada é grande, porém o número de espécies por fragmento é pequeno.

As espécies encontradas no presente estudo foram citadas em outros trabalhos realizados no Rio Grande do Sul, Santa Catarina e Paraná (VASCONCELLOS et al., 1992; FARIAS et al., 1994; DIAS et al., 1998; JARENKOW; WAECHTER, 2001; BELOTTI et al., 2002; JURINITZ; JARENKOW, 2003; RUSCHEL et al., 2006; 2009; VIBRANS et al., 2008; SCHORN et al., 2012a; 2012b), indicando que as mesmas não são restritas à área amostrada e nem ao estado de Santa Catarina.

Myrtaceae e Fabaceae estão entre as famílias mais ricas em espécies no Estado de Santa Catarina (REITZ et al., 1978). Na Floresta Estacional do Alto Uruguai, a família Fabaceae está bem representada no estrato das árvores mais altas (KLEIN, 1972) e assume o primeiro lugar em riqueza (VASCONCELLOS et al., 1992). No presente estudo, essas duas famílias foram igualmente as mais ricas, assim como no Inventário Florístico Florestal de Santa Catarina (VIBRANS et al., 2008; GASPER et al., 2012; SCHORN et al., 2012b). A riqueza de Fabaceae foi verificada também em outras formações florestais, como: Floresta Estacional Semidecidual (FES), Floresta Ombrófila Densa Submontana (FODS) e Floresta Ombrófila Mista (FOM) (JARENKOW; WAECHTER, 2001; RUSCHEL, 2003; CARVALHO et al., 2006; FAGUNDES et al., 2007; ROLIM, 2006; VASCONCELLOS et al., 1992; GASPER et al., 2013). Já na Floresta Estacional Semidecidual Submontana (FESS), Fabaceae não apresentou destaque, chegando a ter poucos representantes (JURINITZ; JARENKOW, 2003).

Myrtaceae foi a segunda família mais rica na área de estudo, juntamente com Meliaceae. A riqueza da primeira família é semelhante àquela encontrada nos estudos de Vaccaro et al. (1999), Jarenkow e Waechter (2001), Jurinitz e Jarenkow (2003), Brunetto et al. (2004) e Hack et al. (2005), que registraram entre seis e nove espécies da família.

Apesar de Sorocea bonplandii e Gymnanthes concolor serem amplamente reconhecidas como espécies dominantes no sub-bosque da FED (VASCONCELLOS et al., 1992; VACCARO et al., 1999; JARENKOW; WAECHTER, 2001; JURINITZ; JARENKOW, 2003; RUSCHEL et al., 2006; 2009; SCHORN et al., 2012a; 2012b), ambas apresentaram baixa abundância na área estudada. Possivelmente, isto decorre do critério de inclusão de indivíduos adotado no presente estudo, mais restritivo do que os utilizados comumente, não refletindo uma diferença real do sub-bosque desta floresta em relação aos outros inventários já realizados.

Além de Sorocea bonplandii e Gymnanthes concolor, Jarenkow e Waechter (2001) citaram Euterpe edulis Mart. (palmiteiro) como uma das espécies mais abundantes (434 indivíduos) da Floresta Estacional localizada na encosta meridional do Planalto Sul Brasileiro. No Alto Uruguai, E. edulis ocorria em manchas esparsas, porém atualmente é provável que esteja extinto na região (KLEIN, 1972). Além do palmiteiro, também não foi registrado na área amostrada Dicksonia sellowiana Hook. (xaxim), outra espécie de importância economia e ecológica. No estudo de Schorn et al. (2012b), foram registrados quatro indivíduos desta espécie. Os autores destacam que embora este número seja baixo, a FED não é a região fitoecológica preferencial de D. sellowiana, que ocorre preferencialmente na Floresta Ombrófila Mista, em altitudes elevadas (GASPER et al., 2011).

Sorocea bonplandii, Nectandra megapotamica, Syagrus romanzoffiana e Trichilia claussenii apresentaram os maiores números de indivíduos e apareceram também entre as espécies mais frequentes na área. De acordo com Ruschel et al. $(2006 ; 2009)$ e 
Vaccaro et al. (1999), essas espécies, exceto a primeira, são climácicas e ocorrem somente quando o dossel da floresta está totalmente desenvolvido, indicando estádio sucessional avançado. Entretanto, Schorn et al. (2012b) classificaram essas mesmas espécies como pertencentes aos grupos ecológicos das pioneiras e das secundárias, assim como a grande maioria das espécies amostradas no presente estudo (Tabela 1).

Durante os trabalhos de campo, foi observado que a área de estudo apresentava características de estádio sucessional avançado de desenvolvimento, conforme descrito por Clark (1996), com o predomínio de árvores com diâmetro e altura elevados, além da presença abundante de epífitos vasculares. Porém, como grande parte das espécies foi classificada como pioneira e secundária, optou-se pela aplicação da equação de Sevegnani et al. (2012), para auxiliar na definição do estádio sucessional. O valor obtido $(5,31)$ indicou estádio sucessional avançado.

Independentemente de serem espécies climácicas ou secundárias, Nectandra megapotamica e Syagrus romanzoffiana estão entre as com mais altos valores de importância na área de estudo, e pertencem ao grupo de plantas mais características do estádio avançado no Oeste de Santa Catarina. Além destas, podem ser citadas outras, como Luehea divaricata Mart. \& Zucc., Nectandra lanceolata, Ocotea puberula (Rich.) Nees, Chrysophyllum marginatum, Machaerium stipitatum, Cabralea canjerana, Cedrela fissilis e Cupania vernalis Cambess. (SEVEGNANI et al., 2012).

Além disso, as proporções de espécies pioneiras (24,07\%), secundárias $(53,70 \%)$ e climácicas $(9,25 \%)$ do componente arbóreo/arbustivo são semelhantes àquelas citadas por Schorn et al. (2012b), que foram $28,42 \%, 56,31 \%$ e $15,26 \%$, respectivamente. Conforme os mesmos autores, tais resultados corroboram o estado atual de degradação da FED, uma vez que a floresta caracterizou-se pela elevada abundância de um pequeno número de espécies pioneiras e secundárias, diferindo de descrições feitas por outros autores em décadas passadas, como é o caso de Reitz et al. (1978).

O percentual de espécies com apenas um indivíduo amostrado neste estudo foi de $45,28 \%$ e este percentual está entre os mais altos em relação a outros estudos, entre eles Vasconcellos et al. (1992), Jarenkow e Waechter (2001) e Vibrans et al. (2012a), com 19,67\%, 20\% e $18,85 \%$ das espécies representadas por um só indivíduo, respectivamente. A grande proporção de espécies com um indivíduo pode estar relacionada a diferenças no esforço amostral, visto que os estudos citados avaliaram, no mínimo, o dobro do número de indivíduos inventariados no presente estudo e sabe-se que o número de espécies raras tende a diminuir e se estabilizar com o aumento do esforço amostral (GOTELLI; COLWELL, 2001). Sendo assim, seria necessário aumentar o esforço amostral para determinar se essas as espécies representadas por apenas um indivíduo são realmente raras regionalmente ou se isto decorre dos métodos de pesquisa utilizados.

Schefflera morototoni foi encontrada com poucos indivíduos neste trabalho. O mesmo aconteceu nos estudos de Jarenkow e Waechter (2001), Jurinitz e Jarenkow (2003) e Hack et al. (2005). Além desta, outras espécies foram consideradas por Klein (1972) como possuindo ocorrência rara na Floresta Estacional do Alto Uruguai, entre elas Rauvolfia sellowii, Holocalyx balansae, Trichilia catigua e Styrax leprosus. Estas apresentaram apenas um ou dois indivíduos na área de estudo.

Nectandra megapotamica e Ocotea diospyrifolia apresentaram os maiores valores de dominância. Embora se saiba que este parâmetro, ao considerar a área basal, valoriza as espécies com maior porte, ou aquelas com altas densidades (VASCONCELLOS et al., 1992), a dominância de Nectandra megapotamica deve-se, em parte, à elevada abundância desta espécie, visto que os indivíduos apresentaram baixos valores de área basal. A densidade de Nectandra megapotamica também explica os altos índices em relação ao valor de importância e cobertura. Dado o caráter pioneiro de Nectandra megapotamica (SCHORN et al., 2012a; 2012b; MEYER et al., 2012) e o potencial da espécie para atingir grande porte, estes resultados provavelmente refletem interferências antrópicas em décadas passadas.

Nos estudos de Vibrans et al. (2008) e Schorn et al. (2012b), Nectandra megapotamica também apareceu entre as primeiras em dominância e valor de importância. Além dessa espécie, outras se descaram na estrutura da 
FED, tais como: Luehea divaricata, Cupania vernalis, Ocotea puberula, Nectandra lanceolata, Machaerium stipitatum, Syagrus romanzoffiana, Cedrela fissilis, Parapiptadenia rigida e Casearia sylvestris (VIBRANS et al., 2012c). Tais espécies, de acordo com Vibrans et al. (2012c), são generalistas, sendo beneficiadas pela abertura de clareiras e comuns em bordas de floresta. Das espécies citadas, as três primeiras não foram encontradas na área amostrada e as restantes não estiveram entre as mais abundantes ou com maior cobertura no presente estudo. Isso também pode ser resultado do esforço amostral ou, possivelmente, do melhor estado de conservação do fragmento, reduzindo o valor de importância das espécies generalistas.

É importante destacar também que Apuleia leiocarpa está entre as dez primeiras em valor de importância no presente estudo, com sete indivíduos. Contudo, no Inventário Florestal de Santa Catarina, a mesma não esteve entre as mais importantes, tendo quatro indivíduos em duas unidades amostrais. Tal espécie foi citada por Klein (1972) como importante, e sua redução pode ser atribuída à intensa exploração e fragmentação dessas florestas (SEVEGNANI et al., 2012).

Quanto aos indivíduos com baixo valor de importância (menor que dois), estes representaram mais da metade $(65 \%)$ das espécies do presente estudo. O Inventário Florestal de Santa Catarina apresentou 36\% das espécies com valores inferiores a dois. Segundo Vibrans et al. (2008), tais valores podem indicar que existe grande vulnerabilidade de suas populações, diante do processo de fragmentação e degradação dos remanescentes florestais na região, tanto da FOM quanto da FED.

A distribuição dos indivíduos em classes de alturas permitiu reconhecer três grupos de árvores que podem representar os estratos arbóreos na floresta, um inferior, um médio e um superior, sendo que a maior porcentagem de indivíduos foi encontrada no estrato inferior ( 5 a 12 $\mathrm{m})$. Observou-se distribuição semelhante no trabalho de Jarenkow e Waechter (2001), que também apresentou a maior parte dos indivíduos no estrato inferior. No estrato superior foi verificada a presença de alguns indivíduos com alturas entre 25 e $30 \mathrm{~m}$, a maioria pertencente às Fabaceae.
O índice de Shannon-Weaver $\left(H^{\prime}\right)$ encontrado foi elevado (3,47 nats) quando comparado ao de outros trabalhos (e.g., VACCARO et al., 1999; JARENKOW; WAECHTER, 2001; SILVA; NASCIMENTO, 2001; JURINITZ; JARENKOW, 2003; SILVA; SCARIOT, 2003), o que provavelmente deve-se à elevada equabilidade da comunidade estudada. Com relação ao Inventário Florestal de Santa Catarina (SCHORN et al., 2012b), os resultados obtidos (entre 2,3 e 3,66) foram semelhantes aos aqui apresentados, enquanto Vasconcellos et al. (1992), Hack et al. (2005) e Ruschel et al. (2006) obtiveram índices de diversidade mais elevados (Tabela 3). Porém, sabe-se que há uma série de limitações na aplicação de índices de diversidade e mesmo na sua comparação, especialmente em função de não sabermos qual parâmetro, riqueza ou equabilidade, afetou mais cada um dos valores de diversidade citados (Melo, 2008).

Nossos resultados indicam que a área estudada, apesar de seu contexto de isolamento e fragmentação, conserva importante parcela das espécies citadas para a Floresta Estacional do Alto Uruguai. É importante que o poder público estabeleça políticas para a preservação dos maiores fragmentos remanescentes de Floresta Estacional Decidual da região, sendo este aqui analisado, indubitavelmente, um dos mais indicados para tal fim.

\section{Referências}

APG III - The Angiosperm Phylogeny Group. An update of the Angiosperm Phylogeny Group classification for the orders and families of flowering plants: APG III. Botanical Journal of the Linnean Society, London, v. 161, p. 105-121, 2009.

BELOTTI, A.; VERONA, L. S. S.; BIEGER, B.; ARGENTON, M. J.; VARNIER, M. L. Estudo fitossociológico e florístico da mata ciliar do lago da Barragem Engenho Braun do Lajeado São José Chapecó, SC. Acta Ambiental Catarinense, Chapecó, v. 1, n. 1, p. 43-58, 2002.

BRUNETTO, R. S.; BELOTTI, A.; SOBRAL, L. S.; GOTTARDI, E. Estrutura florística e fitossociológica de remanescentes da mata ciliar do lajeado São José - Chapecó (SC). Revista Unopar Científica Ciências Biológicas e da Saúde, Londrina, v. 5/6, n. 1, p. 69-76, 2004.

CARVALHO, F. A.; NASCIMENTO, M. T.; BRAGA, J. M. A. Composição e riqueza florística do componente arbóreo da Floresta Atlântica submontana na região de Imbaú, Município de Silva Jardim, RJ. Acta Botanica Brasilica, Feira de Santana, v. 20, n. 3, p. 727-740, 2006. 
CLARK, D. B. Abolishing virginity. Journal of Tropical Ecology, Winchelsea, v. 12, p. 735-739, 1996.

DIAS, M. C.; VIEIRA, A. O. S.; NAKAJIMA, J. N.; PIMENTA, J. A.; LOBO, P. C. Composição florística e fitossociologia do componente arbóreo das florestas ciliares do rio Iapó, na bacia do rio Tibagi, Tibagi, PR. Revista Brasileira de Botânica, São Paulo, v. 21, n. 2, p. 183-195, 1998.

FAGUNDES, L. M.; CARVALHO, D. A.; VAN DEN BERG, E.; MARQUES, J. J. G. S. M.; MACHADO, E. L. M. Florística e estrutura do estrato arbóreo de dois fragmentos de florestas decíduas às margens do rio Grande, em Alpinópolis e Passos, MG, Brasil. Acta Botanica Brasilica, Feira de Santana, v. 21, n. 1, p. 65-78, 2007.

FARIAS, J. A. C., TEIXEIRA, I. F.; FILHO, A. A. Estrutura fitossociológica de uma floresta estacional decidual na região de Santa Maria, RS. Ciência Florestal, Santa Maria, v. 4, n.1, p. 109128, 1994.

FIDALGO, O.; BONONI, V. L. R. Técnicas de coleta, preservação e herborização de material botânico. São Paulo: Instituto de Botânica, 62 p. 1984.

FUNDAÇÃO SOS MATA ATLÂNTICA. Atlas da evolução dos remanescentes florestais e ecossistemas associados no domínio da Mata Atlântica: período de 1990-1995. São Paulo: INPE/ Fundação SOS Mata Atlântica, 55, p. 1998.

FUNDAÇÃO SOS MATA ATLÂNTICA. Atlas da evolução dos remanescentes florestais e ecossistemas associados no domínio da Mata Atlântica: período de 2000-2005. São Paulo: INPE/ Fundação SOS Mata Atlântica, 2005. Disponível em <www. socioambiental.org >. Acesso em: outubro de 2007.

GASPER, A. L.; SEVEGNANI, L.; MEYER, L.; SOBRAL, M. G.; VERDI, M.; SANTOS, A. S.; DREVECK, S.; KORTE, A.; UHLMANN, A. Flora vascular da Floresta Estacional Decidual em Santa Catarina. In: VIBRANS, A. C.; SEVEGNANI, L.; GASPER, A. L.; LINGNER, D. V. (Ed.). Vol. 2. Cap. 4. Inventário florístico Florestal de Santa Catarina. Blumenau: Universidade Regional de Blumenau, 2012. p. 115-126.

GASPER, A. L.; SEVEGNANI, L.; VIBRANS, A. C.; SOBRAL, M.; UHLMANN, A.; LINGNER, D. V.; RIGON-JÚNIOR, M. J.; VERDI, M.; STIVAL-SANTOS, A.; DREVECK, S.; KORTE, A. Inventário florístico florestal de Santa Catarina: espécies da Floresta Ombrófila Mista. Rodriguésia, Rio de Janeiro, v. 64, n. 2, p. 201-210, 2013.

GASPER, A. L.; SEVEGNANI, L.; VIBRANS, A. C.; UHLMANN, A; LINGNER, D. V.; VERDI, M.; DREVECK, S.; SANTOS, A. S.; BROGNI, E.; SCHMITT, R.; KLEMZ, G. Inventário de Dicksonia sellowiana Hook. em Santa Catarina. Acta Botanica Brasilica, Feira de Santana, v. 25, n. 4, p. 776-784, 2011.

GOTELLI, N. J.; COLWELL, R. K. Quantifying biodiversity: procedures and pitfalls in the measurement and comparison of species richness. Ecology Letters, Montpellier, v. 4, n. 4, p. 379391, 2001.

HACK, C.; LONGHI, S. J.; BOLIGON, A. A.; MURARI, A. B.; PAULESKI, D. T. Análise fitossociológica de um fragmento de Floresta Estacional Decidual no município de Jaguari, RS. Ciência Rural, Santa Maria, v. 35, n. 5, p. 1083-1091, 2005.

JARENKOW, J. A.; WAECHTER, J. L. Composição, estrutura e relações florísticas do componente arbóreo de uma floresta estacional no Rio Grande do Sul, Brasil. Revista Brasileira de Botânica, São Paulo, v. 24, n. 3, p. 263-272, 2001.

JURINITZ, C. F.; JARENKOW, J. A. Estrutura do componente arbóreo de uma floresta estacional na Serra do Sudeste, Rio Grande do Sul, Brasil. Revista Brasileira de Botânica, São Paulo, v. 26, n. 4, p. 475-487, 2003.

KLEIN, R. M. Árvores nativas da Floresta Subtropical do Alto Uruguai. Sellowia, Itajaí, v. 24, p. 9-96, 1972.

KLEIN, R. M. Mapa fitogeográfico do estado de Santa Catarina. Flora Ilustrada Catarinense. Itajaí: IOESC, 24 p. 1978.

MACHADO, S. A. Inventário florestal nacional: florestas plantadas. Paraná, Santa Catarina. Brasília: IBDF, 283 p. 1984.

MARTINS, F. R. Estrutura de uma floresta mesófila. Campinas: UNICAMP, 1991. 246 p.

MELO, A. S. O que ganhamos 'confundindo' riqueza de espécies e equabilidade em um índice de diversidade. Biota Neotropica, Campinas, v. 8, n. 3, p. 21-27, 2008.

MEYER, L.; GASPER, A. L.; SEVEGNANI, L.; SCHORN, L. A.; LINGNER, D. V.; VIBRANS, A. C.; VERDI, M.; SANTOS, A. S.; DREVECK, S.; KORTE, A. Regeneração natural da Floresta Estacional Decidual em Santa Catarina. In: VIBRANS, A. C.; SEVEGNANI, L.; GASPER, A. L.; LINGNER, D. V. (Ed.). Vol. 2. Cap. 7. Inventário florístico Florestal de Santa Catarina. Blumenau: Universidade Regional de Blumenau, 2012. p. 167-187. PIELOU, E. C. An introdution to mathematical ecology: New York: Wiley-Interscience. p. 286, 1969.

REITZ, R.; KLEIN, R. M.; REIS, A. Projeto madeira de Santa Catarina. Sellowia, Itajaí, v. 28, p. 1-320, 1978.

RODRIGUES, R. R.; SHEPHERD, G. J. Fatores condicionantes da vegetação ciliar. In: RODRIGUES, R. R.; LEITÃO FILHO, H. F.; LIMA, R. I. M. G.; KON, S. (Ed.). Matas ciliares: conservação e recuperação. 2 ed. São Paulo: EDUSP, 2001. p. 101-105.

ROLIM, S. G.; IVANAUSKAS, N. M.; RODRIGUES, R. R.; NASCIMENTO, M. T.; GOMES, J. M. L.; FOLLI, D. A.; COUTO, H. T. Z. Composição florística do estrato arbóreo da Floresta Estacional Semidecidual na planície aluvial do Rio Doce, Linhares, ES, Brasil. Acta Botanica Brasilica, Feira de Santana, v. 20, p. 549-561, 2006.

RUSCHEL, A. R. Evolução do uso e valorização das espécies madeiráveis da Floresta Estacional do Alto Uruguai. Ciência Florestal, Santa Maria, v. 13, n. 1, p. 153-166, 2003.

RUSCHEL, A. R.; GUERRA, M. P.; NODARI, R. O. Estrutura e composição florística de dois fragmentos da Floresta Estacional Decidual do Alto Uruguai, SC. Ciência Florestal, Santa Maria, v. 19, n. 2, p. 225-236, 2009.

RUSCHEL, A. R.; NODARI, R. O.; MOERSCHBACHER, B. M. Woody plant species richness in the Turvo State park, a large remnant of deciduous Atlantic forest, Brazil. Biodiversity and Conservation, New York, n. 16, p. 1699-1714, 2006.

SANTA CATARINA. Atlas de Santa Catarina. Rio de Janeiro: Aerofoto Cruzeiro. 173 p. 1991.

SCHORN, L. A.; GASPER, A. L.; MEYER, L.; VIBRANS, A. C. Síntese da estrutura dos remanescentes florestais em Santa Catarina. In: VIBRANS, A. C.; SEVEGNANI, L.; GASPER, A. L.; LINGNER, D. V. (Ed.). Vol. 1. Cap. 7. Inventário florístico Florestal de Santa Catarina. Blumenau: Universidade Regional de Blumenau, 2012a. p. 125-137. 
SCHORN, L. A.; LINGNER, D. V.; VIBRANS, A. C.; GASPER, A. L.; SEVEGNANI, L.; SOBRAL, M. G.; MEYER, L.; CLEMZ, G.; SCHMIDT, R.; ANASTÁCIO JUNIOR, C.; PASQUALLI, V. R. Estrutura do componente arbóreo/arbustivo da Floresta Estacional Decidual em Santa Catarina. In: VIBRANS, A. C.; SEVEGNANI, L.; GASPER, A. L.; LINGNER, D. V. (Ed.). Vol. 2. Cap. 6. Inventário florístico Florestal de Santa Catarina. Blumenau: Universidade Regional de Blumenau, 2012b. p. 143-156.

SEVEGNANI, L.; VIBRANS, A. C.; UHLMANN, A.; GASPER, A. L.; MEYER, L.; LINGNER, D. V.; SANTOS, A. S.; VERDI, M.; DREVECK, S. Estádios sucessionais da Floresta Estacional Decidual em Santa Catarina. In: VIBRANS, A. C.; SEVEGNANI, L.; GASPER, A. L.; LINGNER, D. V. (Ed.). Vol. 2. Cap. 9. Inventário florístico Florestal de Santa Catarina. Blumenau: Universidade Regional de Blumenau, 2012. p. 213-217.

SHANNON, C.E.; WEAVER, W. The mathematical theory of communication. Urbana: University of Illinois Press, 117 p. 1949.

SILVA, G. C.; NASCIMENTO, M. T. Fitossociologia de um remanescente de mata sobre tabuleiros no norte do estado do Rio de Janeiro (Mata do Carvão). Revista Brasileira de Botânica, São Paulo, v. 24, n. 1, p. 51-62, 2001.

SILVA, L. Á.; SCARIOT, A. Composição florística e estrutura da comunidade arbórea em uma Floresta Estacional Decidual em afloramento calcário (Fazenda São José, São Domingos, GO, bacia do rio Paraná). Acta Botanica Brasilica, Feira de Santana, v. 17, n. 2, p. 305-313, 2003.

VACCARO, S.; LONGHI, S. J.; BRENA, D. A. Aspectos da composição florística e categorias sucessionais do estrato arbóreo de três subseres de uma floresta estacional decidual, no município de Santa Tereza - RS. Ciência Florestal, Santa Maria, v. 9, n. 1, p. 1-18, 1999.
VASCONCELLOS, J. M. O.; DIAS, L. L.; SILVA, C. P.; SOBRAL, M. Fitossociologia de uma área de mata subtropical no Parque Estadual do Turvo - RS. Revista do Instituto Florestal, São Paulo, v. 4, p. 252-259, 1992.

VELOSO, H. P.; GÓES-FILHO, L. Fitogeografia brasileira classificação fisionômico-ecológica da vegetação neotropical. Boletim Técnico do Projeto RADAMBRASIL, sér. Vegetação, Rio de Janeiro, v. 1, n. 1, p. 1-80, 1982.

VIBRANS, A. C.; LINGNER, D. V.; MOSER, P.; GESSNER, C. M. Estrutura diamétrica dos remanescentes da Floresta Estacional Decidual em Santa Catarina. In: VIBRANS, A. C.; SEVEGNANI, L.; GASPER, A. L.; LINGNER, D. V. (Ed.). Inventário florístico Florestal de Santa Catarina. Vol. 2. Cap. 8. Blumenau: Universidade Regional de Blumenau, 2012a. p. 25-75.

VIBRANS, A. C.; McROBERTS, R. E.; LINGNER, D. V.; NICOLETTI, A. L.; MOSER, P. Extensão Original e remanescente da Floresta Estacional Decidual em Santa Catarina. In: Inventário Florístico Florestal de Santa Catarina. Vol. 2. Cap. 1. Blumenau: Universidade Regional de Blumenau, 2012b. p. 191-210.

VIBRANS, A. C.; SEVEGNANI, L.; GASPER, A. L. Considerações finais sobre a Floresta Estacional Decidual em Santa Catarina. In: VIBRANS, A. C.; SEVEGNANI, L.; GASPER, A. L.; LINGNER, D. V. (Ed.). Vol. 2. Cap. 10. Inventário florístico Florestal de Santa Catarina. Blumenau: Universidade Regional de Blumenau, 2012c. p. 229-232.

VIBRANS, A. C.; UHLMANN, A.; SEVEGNANI, L.; MARCOLIN, M.; NAKAJIMA, N.; GRIPPA, C. R.; BROGNI, E.; GODOY, M. B. Ordenação dos dados de estrutura da Floresta Ombrófila Mista partindo de informações do Inventário FlorísticoFlorestal de Santa Catarina: resultados de estudo-piloto. Ciência Florestal, Santa Maria, v. 18, n. 4, p. 511-523, 2008. 